\title{
AC 2009-1202: SERVICE LEARNING AND SUSTAINABILITY: STRIVING FOR A BETTER FUTURE
}

\section{Jennifer Christensen, Texas A\&M University}

Jennifer Christensen received her BS degree in Chemical Engineering from Artie McFerrin Department of Chemical Engineering at Texas A\&M University in December 2008. She served as President in AIChE Student Chapter in 2007-2008 academic year. She has significantly contributed to the implementation of the service learning both as a directed studies student and also as a teaching assistant and a mentor to the participating students since Fall 2006 semester. Jennifer is the recipient of the 2008-2009 Craig C. Brown Outstanding Senior Engineer Award. Jennifer is currently a student in George Bush School of Government at Texas A\&M. She plans to attend graduate school in Fall 2009.

\section{Lale Yurttas, Texas A\&M University}

Lale Yurttas is a Senior Lecturer and Assistant Department Head for Upper Division in the Chemical Engineering Department at Texas A\&M University. She chairs the Departmental ABET Committee. She serves as an advisor to AIChE Student Chapter at Texas A\&M. She has been the driving force for service learning initiative in College of Engineering. She coordinates the service learning activities for the current NSF Departmental Level Curriculum Project in the Department. She has 12 years of experience in engineering education and curriculum development. Her current interests are project-based learning, experiential learning, and curriculum development. 


\title{
Service-learning and Sustainability: Striving for a Better Future
}

\author{
Jennifer Christensen and Lale Yurttas \\ Artie McFerrin Department of Chemical Engineering, Texas A\&M
}

\begin{abstract}
The Artie McFerrin Department of Chemical Engineering has a vested interest in the development of service learning in order to bring the real-world issues of today's modern society into the classroom, to reinforce engineering principles, and to emphasize engineers' ultimate responsibility in the development of future technologies. The department has various goals that relate to the National Science Foundation (NSF) engineering education project grants. These particular goals include increasing retention rates of engineering students, reinforcing societal responsibilities, building networking skills through teamwork and community relations, and creating a general excitement for engineering. Service learning has been the staple methodology of reaching these goals, as projects have been implemented in the introductory material and energy balances courses from the fall of 2006.
\end{abstract}

The service learning projects assigned to the introductory classes have focused on various issues that are prevalent in today's world, mainly the application of sustainability. In the first iterations of the service learning implementation, Habitat for Humanity, the project partner, challenged students to design an affordable green home. Sustainability and green engineering were the underlying themes of this project Emphasis was placed on researching and proposing viable alternative energy sources, techniques for energy and water conservation, and architectural considerations to increase the overall efficiency of the home.

End-of semester student surveys indicated that the students desired a more refined project to help focus their efforts in a semester's time. One of the energy saving proposals of the Habitat for Humanity project was the use of compact fluorescence light bulbs (CFLs) as alternatives to incandescent light bulbs. The lack of public awareness with regards to environmental impacts due to improper CFL disposal, the lack of a proper recycling program in our local community, and the need for a more focused project resulted in a partnership with the City of College Station on a new service learning project.

Consequently, during the fall of 2008, the introductory class was assigned a project to investigate the environmental impacts of CFLs and incandescent light bulbs through life cycle assessment analyses. Adapting the project to past classes' suggestions, the light bulb analysis project had a narrower, more focused scope; however, the project still met all the objectives and goals espoused above. The project provided opportunities to practice course material on a real-life problem, introduced students to environmental sustainability and project management, and provided opportunities to practice oral and written communication, as well as client relationships. This paper focuses on the learnings from the first iterations of service learning implementation and the incorporation of those learnings into the second iteration, as well as the continued effort to promote the concepts and ideas of sustainability at the most influential stage of a student's academic career. 


\section{Introduction and Background}

In this modern era, it is evident that the problems facing society bridge the traditional divisions of academia and require the collaboration between many independent academic sectors, as well as the reform of traditional engineering curriculum. Coyle, Jamieson, and Oakes ${ }^{[1]}$ formulated the EPICS (Engineering Projects in Community Service) program at Purdue University in order to address the changes facing the modern engineering student at the societal interface. Others, such as Bauer, Moskal, and Gosink ${ }^{[2]}$, have identified the lack of societal understanding and responsibility as a problem within engineering disciplines that has lead to the potential decrease in enrollment rates, and therefore, have studied the effectiveness of service-learning in remediating these deficiencies. Schaad, Franzoni, Paul, Bauer, and Morgan ${ }^{[3]}$ from Duke University have taken service-learning to the next step by implementing the concepts and learning objectives into an interdisciplinary course focusing on the aftermath of Hurricane Katrina. Service-learning implementation in traditional classroom settings brings a new set of challenges to faculty and students. However, the need for a holistic approach to designing engineering curriculum and learning experiences to create a better-rounded engineer is identified and analyzed by Vanasupa, Stolk and Herter ${ }^{[4]}$ through the development of the Four-Domain Development Diagram. Curriculum and learning experience development processes, such as the Four-Domain Development Diagram, as well as Malicky, Lord, and Huang's ${ }^{[5]}$ pedagogy decision matrix, can help formulate more effective service-learning projects to better meet overall learning objectives. This leads into the focus topic of this paper: the compared results of service learning project optimization in an introductory chemical engineering course to better fulfill learning objectives.

The Artie McFerrin Department of Chemical Engineering at Texas A\&M University has a total enrollment of approximately 605 students with 479 undergraduates participating in a 132 hour program. In 2006, the department received an NSF engineering educational grant, in which service learning was earmarked as one of the methods to enrich the overall curriculum quality ${ }^{[6]}$. Service learning is an educational application of engineering principles and concepts through real-life, community and service based projects. These projects vary in scale and application, as the community need will determine the scope and overall individual goals of each proposed project. Service learning projects may also support an engineering department's specific program outcomes to satisfy ABET criterion 3. As an example, this department's Program Outcome 9 states that "students will demonstrate recognition of the need for, and an ability to engage in lifelong learning." The department has devised four performance criteria to assess the achievement of Outcome 9. One performance criterion assesses the students' engagement in activities that help educate the public about pressing science and technology issues. In a service learning approach, the education of the public is achieved through community partnership. Such openended projects also encourage students to seek information independently, thus engaging them in life-long learning activities.

After analyzing the specific goals that needed to be achieved, it was determined that service learning would best be introduced in lower-level classes. The departmental structure of upperlevel classes requires specialized attention to those engineering topics, such as kinetics, mass and heat transfer, and thermodynamics, that cannot be compromised by the addition of a project component of such magnitude. In addition, the general engineering principles of the lower-level 
courses can be most readily applied and extrapolated to more general real-life challenges that would be the basis of the service-learning projects. The goals of increasing excitement and retention rates would be also better served by implementing service learning during the most influential time of a student's academic career, which typically coincides with the lower-level courses. Furthermore, the four learning outcomes of the material and energy balances course were defined with the goal of implementing service learning. Specifically outcome 4 is well aligned with such objectives of a service learning project: community engagement, teaming, written and oral communication, life-long learning, and citizenship. Learning outcome 4 states that "our students should be able to work effectively in teams: Recognize the skills needed to function in a modern engineering environment. Develop teaming skills. Recognize engineering roles in society. Develop and practice written and oral communication skills." Life-long learning skills are especially important for students to have successful careers and should be introduced as early as possible in their education. Service learning projects provide means to achieve such objectives and outcomes.

Therefore, the sophomore level introductory material and energy balances course was determined to be the best fit for the implementation of service learning. As the course for implementation was determined, the projects used for the service learning were determined using the process as described in the previous work ${ }^{[7]}$. Most importantly, this paper outlines the initial steps taken to successfully implement a service learning project, including project formulation, promotion, completion, and reflection.

During the fall of 2006, the first iteration of service learning was implemented in the introductory material and energy balances course through a project partnered with Habitat for Humanity that focused on designing an affordable green home. This project was executed by students in subsequent classes from the fall of 2006 to the fall of 2007. Many learnings were compiled during the first iterations of the green home project and will be presented in the following pages.

In the efforts to improve the student experience with the service learning project, the second service learning project was implemented in the introductory material and energy balances course in the fall of 2008. This project focused on the life cycle assessment analysis of CFLs versus incandescent light bulbs, as well as improving local recycling methods. This project was partnered by the City of College Station, Texas.

The overall goal of service learning is to increase the quality of the students' classroom experience by introducing interesting projects that will foster general excitement, reinforce engineering principles, introduce students to societal challenges, teach team-building and networking skills, and foster the students' societal responsibility. Therefore, this paper focuses on improving the service learning projects from iteration to iteration in order to optimally meet all the goals and objectives.

\section{Iteration 1: Green Home \& Habitat for Humanity}

From the fall of 2006 to the fall of 2007, three individual introductory classes worked on designing an affordable green home for Habitat for Humanity to build according to local conditions and budget constraints. The project was designed to be open-ended and to give students all control in creating their design. However, realizing the magnitude of the project, 
certain steps were taken by the faculty and peer teachers to help guide students through the project. Emphasis was placed on the energy and water systems of the home, as this easily reinforced the material and energy balances learned and taught in class. In addition to reiterating engineering principles and concepts, emphasis was placed on finding green alternatives within budget constraints, which inevitably introduced the concepts of sustainability into the students' design choices. The students were given milestones to complete on an incremental basis throughout the semester, thereby enforcing general project management techniques and skills. In addition to this, several lectures given by experts in particular areas of importance to the project were held outside of class time, as a means to give students a general direction and understanding of the project. The best example of this was inviting architecture professors and graduate students to present research on green architecture in homes to the students. Despite being given general guidelines, the rubric for the project focused on creativity in order to stimulate excitement and individual team ownership for their designs.

The culmination of the project consisted of a written report and an oral presentation given to faculty, upperclassmen, and Habitat for Humanity representatives. At the end of the project, students were asked to evaluate the project and offer suggestions as how to make the project better for the next iteration. Student surveys and evaluations are always hard to analyze, as some students will give all perfect or all failing scores to each learning objective. However, there are students who take the time to fairly evaluate a project, and those responses are easily determined and separated from the extremists. In addition to strict ranking type questions, student comments were encouraged, and in this case, were the most valuable in determining the success of the first iteration of service learning.

From the evaluation results, it was evident that the project was a success at meeting most learning objectives, and yet, as in almost every case in academia, room for improvement was identified. The students gave the project above average rankings in all learning objectives on a scale from a 5 being 'strongly agree' and 1 being 'strongly disagree'. However, the learning objective of establishing a connection between chemical engineering discipline and community, people, and values was one of the lowest ranked. Figure 1 shows the ranking of the learning objectives in Table 1. The student comments reinforced their 'somewhat agree' ranking of this learning objective. Most students felt that the designing of a green home was out of the scope of the typical chemical engineering discipline and required a more interdisciplinary team to truly and accurately contribute to the overall design. Students felt that the energy and water balances on the house were relevant to chemical engineering principles, but that more knowledge outside the class focus was needed to effectively choose building materials, floor layouts, etc. 


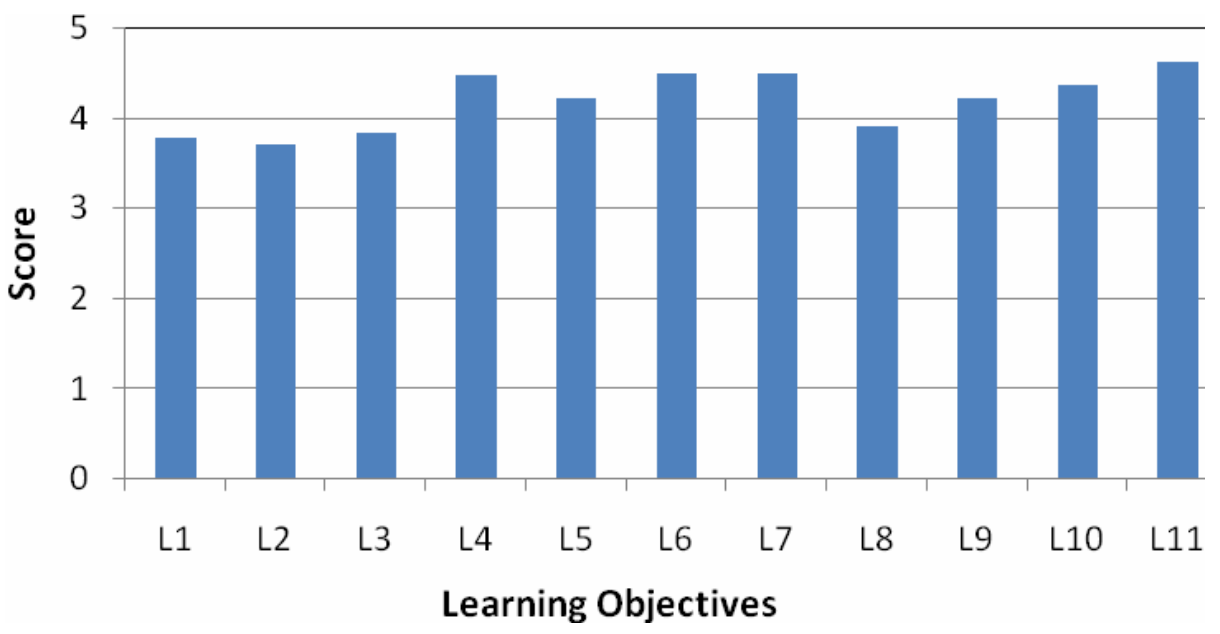

Figure 1: First Iteration Evaluation of Student Learning

1 Learned to work within budget constraints

Table 1: Learning Objectives

2 Applied course material to real-life, open-ended project

3 Established connection between Chemical Engineering discipline and community, people, and values.

4 Learned simple project management tools

5 Enhanced understanding of societal impacts of engineering

6 Demonstrated understanding of environmental and sustainability issues in regard to water and energy conservation, and waste minimization

7 Identified the needs of low-income families and evaluated the importance of volunteer work

8 Better understood how a non-profit organization works

9 Extended experience in written and oral communication with a diverse audience of peers, faculty advisors, and community partners.

10 Learned to acquire information and knowledge independently as deemed by the project

11 Demonstrated ability to function in peer teams

Other students commented on the size of the project being too large and complex to finish in a semester. Students suggested that the scope of the project should be reduced in order to effectively reinforce certain principles, instead of stretching the learning objectives too wide and thinning the students' overall learning capability. Essentially, the students had suffered from scope creep throughout their project experience. In the efforts to create an open-ended, real-life project where students could effectively set their own scope, we actually created a challenge that students could not wrap their minds around. This resulted in long project reports with disjointed information and designs. It was evident through the reports that the students had spent much time on their projects, as individual parts of the designs were well planned, executed, and designed with proper engineering principles and concepts. However, the students had a difficult time deciding what to focus on and what not to, which lead to a lack in the overall cohesiveness of the project results. 
As these critical student comments allowed the project facilitators to hone the objectives for the second project iteration, positive student feedback regarding the service learning and sustainability objectives also fueled the topic for the second iteration. The students felt that through the project their understanding of sustainability and of a chemical engineer's responsibility to support sustainable development had increased. This understanding came not only from the design criteria focusing on alternative energy sources, but also from stressing conservation techniques to the future families that were to live in their designed home. As extra credit, the students provided green living techniques and tips in pamphlets and sheets to be included in the education materials handed out to Habitat families. These green living techniques helped families save on their utility bills and live more responsibly. Figure 2 shows examples of the pamphlets that were designed by students. In addition to this, the students felt that the service learning aspect had helped them to realize their responsibility as engineers to the general public. Most students reflected that they would be more inclined to volunteer their talents and knowledge for other non-profit organizations and community based services.
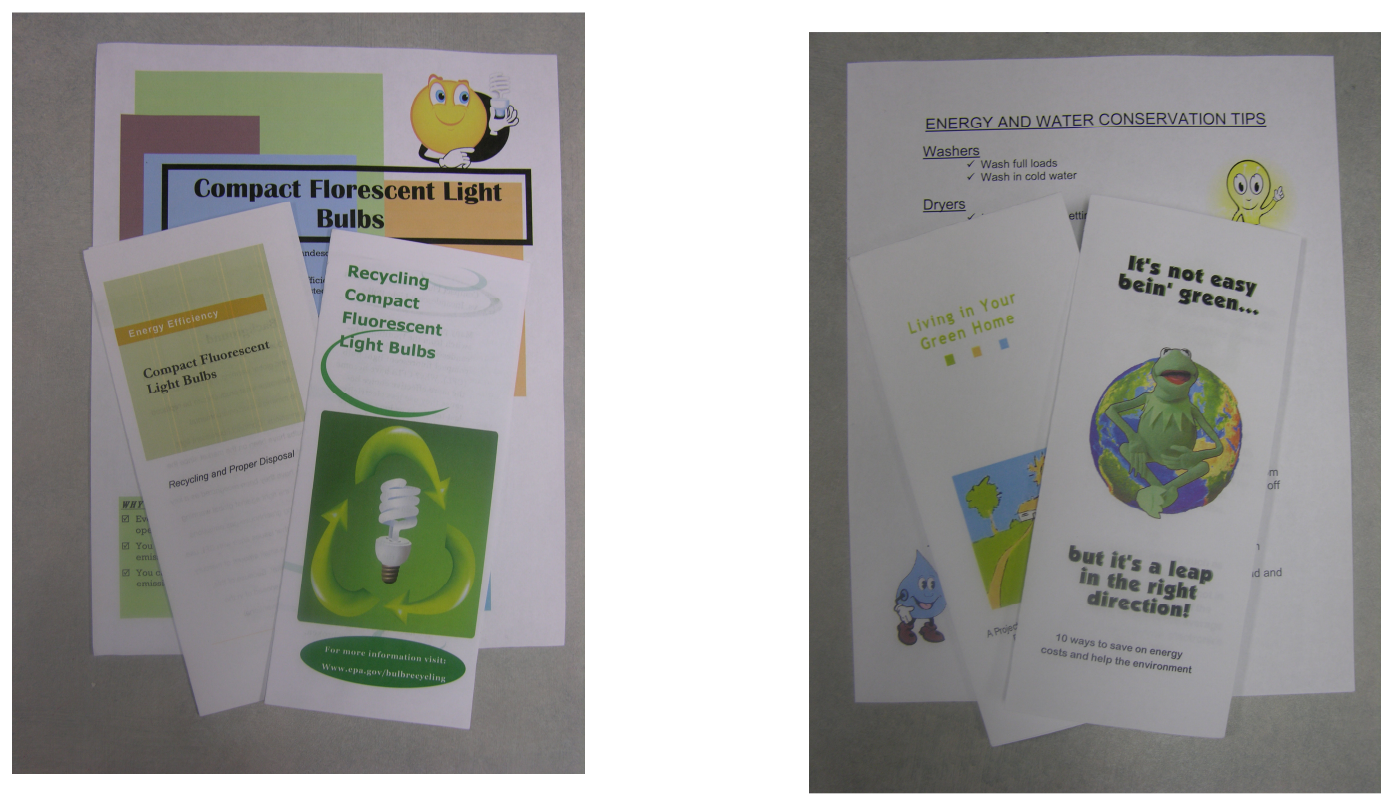

Figure 2: Samples of Public Education Materials Prepared by Student Teams

Therefore, the overall analysis of the first iteration evaluation was that the most significant goals of the project were being fulfilled at an above average success rate. However, there were improvements to make in the design and scope of the project in order to increase the success of the learning objectives and the effectiveness of student learning capability. Taking the student evaluations and comments into account, the second iteration of the implementation of service learning was designed and executed in the fall of 2008 in the introductory material and energy balances class as described in the next section. 
The first project, the Habitat for Humanity green home project, is continued in a college level project-based course, Engineering Projects in Community Service (EPICS), which is modeled after Purdue University's EPICS Program ${ }^{[8]}$. This course was first offered as a pilot in the spring of 2008. Founded on the success of the pilot, it was decided to expand the course to a larger number of multidisciplinary engineering students. Artie McFerrin Department of Chemical Engineering is leading the efforts in the college and plans to offer the course regularly starting in the fall of 2009. As part of their course work, the chemical engineering students from the introductory material and energy balances class will be offered smaller sub-projects that sustain the larger EPICS projects. For example, rather than building an entire house, students in the material and energy balances class may focus on different aspects of the green home, such as floor materials or attic design. Large scale projects such as Habitat green home are feasible in the EPICS course. Students can take EPICS multiple times and may see a project to its completion. Both college level and departmental level service learning implementation may be achieved and sustained through such collaboration.

\section{Iteration 2: CFLs versus Incandescent Light Bulbs \& City of College Station, Texas}

The second iteration of service learning implementation in the introductory material and energy balances class was essentially a spin-off project from the green home design project partnered with Habitat for Humanity. Many of the students' green home designs included the simple switch from using incandescent light bulbs to using CFLs in order to conserve electricity and cut down on utility bills. In efforts to reduce the project scope and to meet the same objectives in a less overwhelming fashion, the second iteration was designed to analyze whether CFLs were greener than incandescent light bulbs as claimed by students in the first iteration of projects.

The project statement had two parts: (1) life cycle assessment on CFLs and incandescent light bulbs and (2) analysis of recycling and public education practices of City of College Station. The project constituted $10 \%$ of the final course grade. Part of the project statement included the following statement: "this is an open-ended project; be as creative as you can be and research the various options through not only the internet and books, but also people. You will submit a report (50\%) and present your project in front of an audience (50\%). Your project presentation will be judged by your fellow students, a team of faculty, and a City of College Station representative. Your project will be evaluated as follows:

- Creativity (40\%)

- Effective use of CHEN concepts (30\%)

- Detail and effort (10\%)

- Written/oral communication skills $(20 \%)$

○ Conveying your ideas to the audience(or the reader)

- Presentation (slides/report)

○ Composure/answers to questions

○ Teaming"

Additionally, three different rubrics were used to evaluate written reports, oral presentations, and teaming $^{[7]}$.

In order to effectively determine which product was actually more environmentally friendly, greener, and more sustainable, the students were required to complete life cycle assessments on each type of light bulb and compare the results. The students were presented with Dr. David T. 
Allen and Dr. David R. Shonnard's method of conducting a life cycle assessment ${ }^{[9]}$. According to Dr. Allen and Dr. Shonnard, there are four main steps in conducting a life cycle assessment: scope and boundary identification, life-cycle inventory, life-cycle impact assessment, and improvement analysis and interpretation ${ }^{[9]}$.

In the scope and boundary identification stage, the basis and system boundaries are determined in order to be able to directly compare the different products being evaluated ${ }^{[9]}$. In determining the system boundaries, students must determine which phases of the life-cycle they will evaluate: whether it is individual phases or the overall life-cycle from raw materials to disposal ${ }^{[9]}$. System boundary identification directly applies the material and energy balances principles and concepts learned in class on a greater scale. In the inventory step, students were asked to identify the particular inputs and outputs, such as raw materials, emissions, wastes, and energy, which they would track throughout the life-cycle in order to determine the overall impact of the product ${ }^{[9]}$. In the life-cycle impact assessment and valuation steps, students were asked to essentially rank the inputs and outputs according to their environmental impact ${ }^{[9]}$. Students were also asked to discuss the differences in impacts and make suggestions in ways these could be reduced to produce a more sustainable and greener product. In this exercise, students were able to act as real-world engineers and identify the scope, boundaries, and inputs and outputs instead of being given them in the form of a homework problem. Their problem-solving skills could be applied in a structured manner in which they could realistically determine a better product and then make a proposal for the future.

As can be imagined, the life cycle assessments conducted by the student groups were not as thorough or accurate as an industrial or academically reliable life cycle assessment would be. However, the comparison of CFLs and incandescent light bulbs has been done before, and therefore, numbers, figures, and facts regarding energy consumption, emissions and waste production could be found by the students through the internet or other available sources. Despite having reliable information, the impact assessment step of the life cycle assessment proved to be challenging due to the complexity of determining an impact score for each chosen emission. The students were not required to obtain the more technically complex information to determine accurate impact scores, but rather were encouraged to use their engineering concepts and research to determine which inputs and outputs posed the greatest threat to the environment and rank them accordingly. Through having readily available and reasonably reliable data, the students were able to perform the steps of a life cycle assessment and draw accurate conclusions regarding the questionable green nature of CFLs. The emphasis of the first part of this project was not necessarily for the students to rigorously complete a high level life cycle assessment, but rather it was to introduce a method in which greener and more sustainable products and processes can be evaluated and designed in order to reduce environmental degradation. Students also successfully used some of the concepts learned in material and energy balances course such as choosing a common basis for comparison of the two products, defining system boundaries, simple material and energy balances on different stages of life cycles, vapor pressure calculations, and ideal gas law applications.

Most student groups effectively applied the life cycle assessment to determine that CFLs were greener than incandescent light bulbs; however, they also recognized the need for recycling the CFLs. This recognition led directly into the second project objective. The local College Station area where Texas A\&M University is located does not have a substantial recycling program that 
is utilized by many people. In fact, as students conducted surveys and researched the recycling program, they began to realize that the problem is not necessarily the existing program, but rather a lack of understanding by the general public that CFLs contain mercury and are harmful if not properly recycled. Therefore, the students were charged with the task of determining ways in which the public could be educated about the potential danger of CFLs, as well as revamping the current recycling system to be more convenient and accessible for the consumer.

The students reacted positively to this second part of the project, as they could think outside of the box in order to reach more people and effectively make a difference in the local community by raising awareness and encouraging recycling. A campus wide survey was initiated by one of the student teams to understand the level of awareness and attitudes among the student population. Most teams focused on ways to reach the large student population, almost 50,000 students, in the College Station area who live in apartment complexes and multi-person accommodations. Students also researched ways to bring down the overall cost of recovering mercury from the CFLs. One student team designed equipment for safe disposal of CFLs. Students also prepared education materials for the city utilities department to include in monthly utility bills, as shown in Figure 2. This part of the project provided the open-ended, real-life application of problem solving, as students were able to invoke their creativity and apply their unique talents. In addition to this, students worked hand-in-hand with the community partner, the City of College Station, to meet common goals.

As can be seen, the student concerns and suggestions from the first iteration were taken into serious consideration for the planning of the second project iteration. The project better focused on directly applying a broader scope of chemical engineering to a specific concern, CFLs versus incandescent light bulbs. Also, in this project, the cross application of engineering skills to different disciplines or unique problems was also discussed. Engineering problems are not always cut-and-dry; there are grey areas that cross disciplines, but the overlying principles and concepts of advanced problem-solving are the same. Therefore, the application of the more generalized life cycle assessment method was able to generate general engineering skills of problem-solving and critical thinking, as well as specific chemical engineering principles of material and energy balances. To stop students from suffering from scope creep, the project was better defined and had less of the open-ended approach than the first iteration. At the same time, the same objectives were accomplished on a more reasonable time scale and work load.

The second iteration project also kept the core issue of sustainability at the forefront, if not perpetuating it more than in the first iteration. In the second project, the learning and completion of the life cycle assessment was a process and method can be applied in industry engineering applications, as well as the classroom. Therefore, the potential learning impact increased, as life cycle assessment is not only information, but an application that the students can carry with them into their industrial and academic careers.

Written reports and oral presentations were the culmination of the second iteration projects. As customary, students filled out an evaluation form and commented on the project in general.

Figure 2 below shows the responses to the learning objectives as displayed in Table 2. The key to the scoring scale as shown in Figure 3 is that 5 corresponds to 'strongly agree', 4 to 'agree', 3 to 'somewhat agree', 2 to 'disagree', and 1 to 'strongly disagree'. 


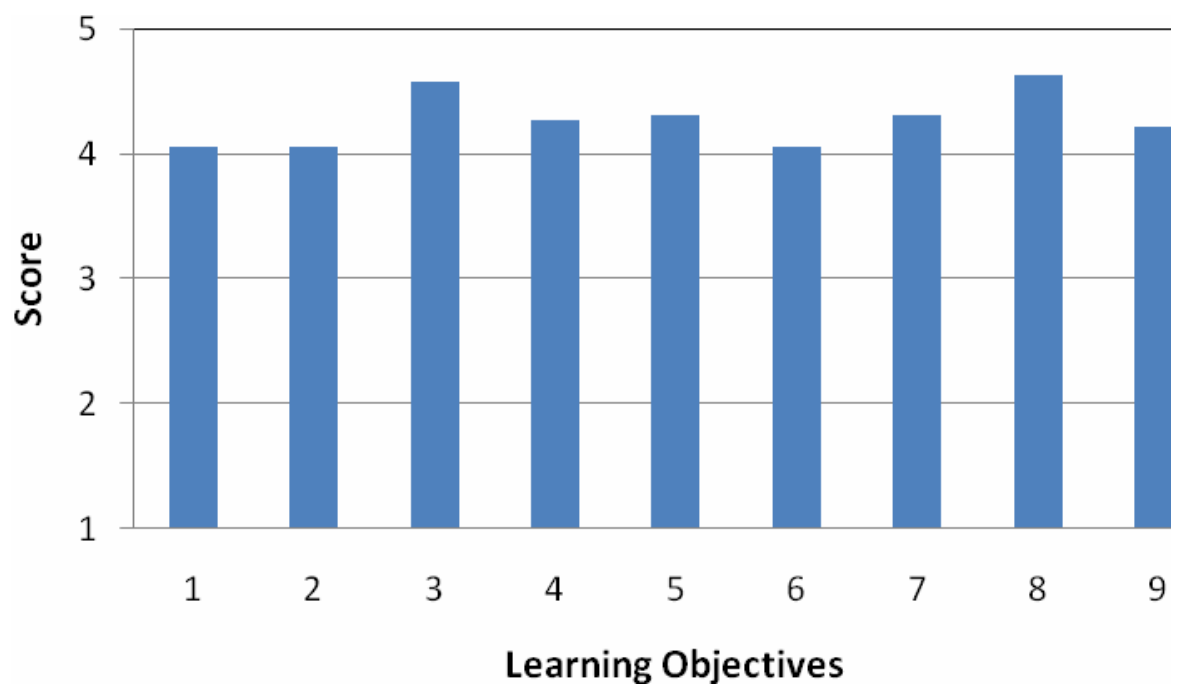

Figure 3: Second Iteration Evaluation of Student Learning

\section{Table 2: Learning Objectives}

1 Apply course material to real-life, open-ended project

2 Establish connection between Chemical Engineering discipline and community, people, and contemporary issues

3 Learn simple project management tools

4 Enhance understanding of societal impacts of engineering

5 Demonstrate understanding of environmental and sustainability issues in today's modern world

6 Better understand how our local government functions and impacts our society

7 Gain experience in written and oral communication with a diverse audience of peers, faculty advisors, and community partners

8 Learn to acquire information and knowledge independently from various sources

9 Demonstrate ability to function in peer teams

Therefore, as can be seen from Figure 1, the learning objectives of the second iteration project were all successfully met with students 'agreeing' to 'strongly agreeing' with the effectiveness of each objective. In addition to this, it can be seen that objective 3 in the first iteration and objective 2 in the second iteration (the same learning objective was numbered differently) has improved from the 'somewhat agree' category to the 'agree' category. Therefore, the measures taken in the second iteration to improve the connection between the chemical engineering discipline and community, people, and contemporary issues were effective. Objective 5 was rated high. This is especially pleasing as the Department is in the process of establishing an "Environmental Sustainability" track and concerned in exposing students to concepts of sustainability throughout the curriculum. 


\section{Student Reflection}

In addition to student surveys, qualitative assessment based on student reflection may be summarized in the following categories. Students were in general agreement in:

- Environment and sustainability. Students felt that the project taught them the necessary steps to complete a life cycle assessment.

- Project management. Students stated that the project helped them with project management, responsibility, and problem solving.

- Teaming and leadership. Students expressed that they gained valuable experience in leadership roles and functioning in teams.

Mixed response was received in

- Creativity. Some students found the project to be somewhat confined and not to have a lot of room for creativity.

- Chemical engineering concepts. Some students felt that they were able to use chemical engineering concepts, and some students thought that the project could have been better related to chemical engineering.

- Community engagement. A number of students thought that the project provided them a valuable opportunity to apply the chemical engineering discipline in College Station community. On the other hand, some others thought that there wasn't a true community need for the project.

This statement from a student may summarize the general student sentiment well:

"This project was challenging yet provided a great opportunity to look at a current issue in the community and to try and find a solution. Admittedly, applying CFL's to chemical engineering seemed like a stretch at first, however after doing research, I felt like I was able to expand my horizons for what chemical engineering can encompass."

\section{Conclusions}

Implementing service learning in chemical engineering curriculum presents several challenges. Difficulty arises in finding the type of projects that would excite students, as well as relate to their major, specifically to the course material. Such projects are not visibly available, and finding them requires creative searching and initiation of dialog with the community organizations. The outcome is well worth the effort, however. Establishing and maintaining relations with the community are essential for the success of such projects. At the end, through this partnership, the community, the students, and the engineering programs all benefit.

In general, the conclusion is that the first and second iterations were successful implementations of service learning in open-ended, real-life projects. The secondary conclusion is that modifying projects between iterations leads to the greater success and achievement of learning objectives established by the department and students. Therefore, perhaps another iteration of the project will be necessary to continue project improvement. 


\section{Acknowledgments}

The authors would like to thank Sheila McQueen and Heather Woolwine of City of College Station Recycling and Public Works Department, Texas. The authors would also like to acknowledge support from the National Science Foundation under Grant No. EEC-0530638. Any opinions, findings, conclusions or recommendations expressed in this material are those of the authors and do not necessarily reflect the views of the National Science Foundation.

\section{References}

1. Coyle, Edward J., Leah H. Jamieson, and William C. Oakes. "EPICS: Engineering Projects in Community Service." International Journal of Engineering Education. 21.1 (2005): 139-150. 12 Mar $2009<$ http://www.ijee.dit.ie/latestissues/Vol21-1/IJEE1549.pdf.>

2. Bauer, E. Heidi, Barbara Moskal, and Joan Gosink. "Faculty and Student Attitudes Toward Community Service: A Comparative Analysis." Journal of Engineering Education (Washington, D.C.) 96.2 (2007): 12940. Education Full Text. H. W. Wilson. 12 Mar $2009<$ http://vnweb.hwwilsonweb.com/>.

3. Schaad, David E., Linda P. Franzoni, Christopher Paul, Anna Bauer, and Kendall Morgan. "A Perfect Storm: Examining Natural Disasters by Combining Traditional Teaching Methods with Service-Learning and Innovative Technology." International Journal of Engineering Education. 24.3 (2008): 450-465. 12 Mar 2009 <http://www.ijee.dit.ie/latestissues/Vol24-3/s2_ijee2008.pdf>.

4. Vanasupa, Linda, Jonathan Stolk, and Roberta J. Herter. "The Four-Domain Development Diagram: A Guide for Holistic Design of Effective Learning Experiences for the Twenty-first Century Engineer." Journal of Engineering Education (Washington, D.C.) 98.1 (2009): 67-81. Education Full Text. H. W. Wilson. 12 Mar 2009 <http://vnweb.hwwilsonweb.com/.>

5. Malicky, David M., Susan M. Lord, and Ming Z. Huang. “A Design Methodology for Choosing an Optimal Pedagogy: the Pedagogy Decision Matrix.” International Journal of Engineering Education. 23.2 (2007): 325-337. 12 Mar 2009 < http://www.ijee.dit.ie/latestissues/Vol23-2/13_ijee1895.pdf.>

6. Yurttas, L. \& Pchenitchnaia, L., (2008) "Chemical Engineering Undergraduate Curriculum Reform, Development and Assessment: A "Strings" Approach." AIChE Annual Conference Centennial Proceedings, Philadelphia, Pennsylvania.

7. Yurttas, L., Christensen, J., Haney, J. S., El-Halwagi, M., Froyd, J. E., \& Glover, C. (2007). "Enhancement of Chemical Engineering Introductory Curriculum through Service-Learning Implementation." Paper presented at the ASEE Annual Conference \& Exposition. Retrieved December 5, 2008, from http://papers.asee.org/conferences/paper-view.cfm?id=4246

8. http://epics.ecn.purdue.edu/

9. Allen, David and D. Shonnard. Green Engineering: Environmentally Conscious Design of Chemical Processes. 2002. Prentice Hall: Upper Saddle River, NJ. p. 419 - 459. 